\title{
Effect of training program on food safety knowledge, behaviour and practices among female students of Qassim University, KSA
}

\author{
${ }^{1}$ Asmahan, A.A., ${ }^{1}$ Wafa, I.E. and ${ }^{1,2}$ Abd El-Razik, M.M. \\ ${ }^{1}$ Department Food Science and Human Nutrition, Faculty of Agriculture and Veterinary Medicine, Qassim \\ University, Saudi Arabia \\ ${ }^{2}$ Department of Food Science, Faculty of Agriculture, Ain Shams University, Cairo, Egypt
}

\begin{abstract}
Article history:
Received: 22 October 2020

Received in revised form: 25

November 2020

Accepted: 21 January 2021

Available Online: 13 June 2021
\end{abstract}

\section{Keywords:}

Behaviour,

Food Safety,

Knowledge,

Practices,

Training

\section{DOI:}

https://doi.org/10.26656/fr.2017.5(3).605

\begin{abstract}
The study aimed to assess the effect of the training program in the level of concerns knowledge and various practices related to food safety among female students of the Food Science and Human Nutrition Department, College of Agriculture and Veterinary Medicine, Qassim University, Saudi Arabia. The number of participants in the study is 265 female students, with a response rate of $94.35 \%$ and an average age of 21 years. The questionnaire used in this study was divided into five sections: 1: demographic information, sections 2 to 5 measuring the students 'concerns about: the risks affecting food safety, the correct behaviours of food preparation and their relationship to food poisoning, the methods of food circulation and the practices during the preparation of foods, respectively. The main concerns of the participants were: food taste, food temperature, methods of foods are served and the cooking degree of food. They also focused on the cleanliness of the area of preparation and the overall appearance of food handlers. The participants showed good knowledge regarding food safety, and they were more familiar with the cleanliness of kitchen surfaces and utensils, ways to prevent contamination and the importance of hand hygiene, but they showed weak knowledge about the appropriate temperatures of cooking and holding food after it is cooked. According to the results of this study, it was noticed that there is a significant effect of the training program on food safety knowledge and practices among students. As it was noticed that after the training program, the student's behaviour and knowledge of the principles and factors affecting food safety increased, including the method of handling, preparing and serving food, especially the cleanliness of food working surfaces and food cooking temperatures. As well as the personal hygiene of food handlers and its impact on the safety of the food product provided for consumption. At the same time, it could be recommended that there is a need for educational programs aimed at encouraging students to adhere to the practice of food safety measures, and not only to enhance their knowledge.
\end{abstract}

\section{Introduction}

Foodborne illnesses are a burden globally to public health and a nation's economy (Young and Waddell, 2016). Research has shown that the increase in foodborne illnesses could be related to improper food safety practices in homes, as home environments can harbour an array of foodborne pathogens (Langiano et al., 2012; Mountjoy, 2014; Young and Waddell, 2016), such as bacteria, viruses and fungi (Byrd-Bredbenner et al., 2013). Food safety knowledge also appears to be inadequate among university students outside of the U.S. for example, both female students in Jordan (37.39 out of
81 (Osaili et al., 2011) and Greek students (6 out of 13) (Lazou et al., 2012) averaged $46 \%$ correct answers to food safety knowledge questions, while Lebanese students averaged 54\% correct answers (Hassan and Dimassi, 2014), and students in Turkey averaged 57\% (11.97 out of 21) (Sanlier and Konaklioglu, 2012). Students in Saudi Arabia averaged 75\% correct answers to 15 knowledge questions (Sharif and Al-Malki, 2010). A study of Spanish health sciences students, that did not report overall knowledge, found $50 \%$ of students knew to wash utensils used for raw materials before cutting cooked products, and that $85 \%$ knew to wash hands before, during, and after food handling and processing 
(Garayoa et al., 2005). Most of the students have adequate knowledge of food safety and good behaviour and practices. However, because these items are assessed based on questions through a questionnaire, many students do not apply perceived knowledge of food safety in their daily practices. It is important for the correct implementation of food safety measures on an ongoing basis, which preserves the safety of the consumer (Nivethitha et al., 2019; Sayuti et al., 2020). At least $30 \%$ of consumers suffer from foodborne diseases in various countries of the world, and this may be due to the consumer's lack of knowledge about the safety and quality of the food provided to them. At the same time, there is a relationship and correlation between knowledge of food safety practices and their food handling and eating of food. Several studies have shown that consumers between the ages of 18-19 years have poor food handling practices even with education above high school level compared to others. Also, most food handlers may not have the experience and information regarding food safety (Sayuti et al., 2020). The media is one of the tools that can be used to educate consumers about food safety. However, this method is considered insufficient and impractical in educating consumers and preserving their safety. Therefore, it is important to raise awareness of food safety practices and maintain consumer safety (Luo et al., 2019; Odeyemi et al., 2019). Cruz (2019) reported that the outbreak of foodborne diseases is due to many factors, the most important of which is insufficient training on food safety procedures. Ellinda-Patra et al. (2020) indicated the need to improve knowledge of food safety in order to improve the behaviour and safety of local communities. However, it is important to recognize that transforming knowledge into behaviour requires other factors such as training in applying food safety principles and practices.

Therefore, this study aimed to assess the effect of the training program at the level of concerns knowledge and various types of practices related to food safety among female students of Qassim University, KSA.

\section{Materials and methods}

\subsection{Participants}

The study started during the academic year 2019/2020. The targets of the study are students of the Department of Food Science and Human Nutrition, Faculty of Agriculture and Veterinary Medicine, Qassim University, Kingdom of Saudi Arabia. The socioeconomic situation was not considered variable in the research and thus all income groups were involved.

The study sample number was calculated according to (Singh and Masuku, 2014) method using the formula for determining the minimum sample size for a population greater than 10,000

$$
\mathrm{n}=\frac{\mathrm{Z}^{2} \mathrm{p}(1-\mathrm{p})}{\mathrm{d}^{2}}
$$

Where $\mathrm{n}$ is the calculated number of participants (sample size), $\mathrm{Z}$ is the abscissa of the normal curve that cuts off an area of the tails and $\mathrm{p}$ is the approximate prevalence rate for which the survey is to be conducted.

The number of female students participating in the study was 265 female students with an average age of 21 years and an academic stage of study levels in the program from the second level to the seventh level.

The closed question method was used in preparing the questionnaire to create quantitative analysis data. Each questionnaire consists of 60 questions, through which the impact of training on food safety practices among students is assessed and assessment of knowledge, awareness and practices related to their food safety without identifying the participants. The participants' identification data included the following: age and social status.

All the participants were informed that the collected data will be used only for research purposes, and the posts were also informed that participation in the questionnaire will not have any effect on their grades as it is Participants had the option not to submit the completed form if they did not wish to do so, and thus by answering the questions, the participants indicated that they agreed to be part of the research, and the confidentiality of the posts was guaranteed by not asking them about their identity.

\subsection{Data collection and questionnaire design}

A questionnaire was designed according to Ovca et al. (2014) and Al-Shabib et al. (2016). The questionnaire was divided into five sections. The first part included demographic data namely participants age, the study was carried out on the female students only, nationality and college of study. The second part focused on the food safety concerns of students. The participants were asked to list their food safety concerns related to the food they buy on campus. The third part comprising six statements evaluated the personal understanding of participants towards food preparation and related risks. Knowledge regarding food safety was evaluated in the fourth part of the questionnaire on the basis of 15 questions. The questions were grouped under six categories, and one question was uncategorized as it was related to food safety responsibility after purchase. Food safety practices were investigated in the fifth part. Using a 3-point scale (never, always and sometimes) the participants reported 
how often they performed the described action and scored from 0 to 2 with higher scores for better practices. The level of practice was classified into the poor level (Less than 59\%), average level (60 to $80 \%$ ) and good level (80 to $100 \%$ ) as described by Gizaw et al. (2014).

\subsection{Design of training program}

The training program was prepared and designed according to Food Standards Australia New Zealand (2002) and Abu Dhabi Food Control Authority (2010). The training program included the following principles: Food safety terminology, Factors affecting food safety, What is the meaning of food poisoning, Food poisoning and its risk to consumer health, Food poisoning and its related to the personal hygiene of the consumer, The most common places where food poisoning occurs, Foods that cause and outbreaks food poisoning and The methods of handling and handling food.

\subsection{Statistical analysis}

Data analysis was performed using SPSS software for Windows, version 20.0. Data is presented as replicates (\%); the chi-square test of independence is used to test the association between gender and select variables. A p-value less than 0.05 was considered statistically significant.

\section{Results and discussion}

\subsection{The personal and social characteristics of the sample members}

The demographic profile of the student participants is shown in Table 1. The distribution of members of the sample of female university students by age group and marital status, as well as their distribution according to the different school years, are shown in Table 1. Given that the study sample is located at a similar age level, this was reflected in most of the studied personal

Table 1. Age group data, marital status and educational level of female students participating in the study

\begin{tabular}{cccc}
\hline $\begin{array}{c}\text { Participant properties } \\
(\mathrm{n}=250 \text { students })\end{array}$ & Category & $\begin{array}{c}\text { Students } \\
\text { number }\end{array}$ & $\%$ \\
\hline \multirow{3}{*}{ Age group } & $18-19$ year & 64 & 25.6 \\
& $20-21$ year & 154 & 61.6 \\
& $22-23$ year & 29 & 11.6 \\
& $\leq 24$ & 3 & 1.2 \\
\hline \multirow{2}{*}{ Social status } & Married & 14 & 5.6 \\
& Unmarried & 236 & 94.4 \\
\hline \multirow{2}{*}{ Nationality } & Saudi & 250 & 100 \\
& Not Saudi & 0 & 0 \\
\hline \multirow{5}{*}{ Academic level } & second & 94 & 37.6 \\
& third & 96 & 38.4 \\
& Fourth & 45 & 18 \\
& Fifth & 7 & 2.8 \\
& Sixth & 2 & 0.8 \\
& Seventh & 6 & 2.4 \\
\hline
\end{tabular}

eISSN: $2550-2166$ characteristics.

Table 1 indicates that most of the female participants in the research are from the 20-21 age group, with a percentage of $61.6 \%$, and that an estimated $1.2 \%$ of the female students under study fall into the 24 and older age group while the average is the age for female students understudy is 21 years, with a percentage of $61.6 \%$ and a standard deviation value (SD 12,1). It is also clear that all female students were of Saudi nationality and the vast majority of them $(94.4 \%)$ were not married. The distribution of the academic level of female students participating in the study is shown in Table 1 , where it was found that the highest percentage of female students were from the third academic level of the program with a percentage estimated at $38.4 \%$. It was followed by students at the second academic level with $37.6 \%$, at the same time, the percentage of female students at the fourth academic level participating in the study was $18 \%$. While it was noted that the participation of female students of the fifth and seventh academic levels was small and was estimated at percentages of 2.8 and $2.4 \%$, respectively. It was also found that the lowest female students participating in the study were those who attended the sixth level and the women were $0.8 \%$.

\subsection{Measuring the students 'concerns about the risks affecting food safety (Food safety concerns)}

Food safety concerns of the students are listed in Table 2. The respondents were investigated for nine food safety concerns that related to food, food handlers and the environment in which the food was being served. Each student was asked to answer which specifies one of the two options with either "Yes it has an effect" or "No that has no effect" on food safety. The measurement results of the students 'concerns about food safety before and after participating in the training program to clarify the extent of the impact of the training on correcting those concerns. It is also clear from the results in Table 2 that the highest percentage of female students before the training process had concerns about the cleanliness of the place of preparation and handling of food and the extent of its impact on food safety from diseases at a rate of $97.2 \%$, at the same time there was no significant difference to the same concerns after a training process $(\mathrm{p}=0.201)$.

On the contrary, the percentage of female students who expressed their concerns about the cleanliness of the tables on which food was eaten before the training process amounted to $95.6 \%$, hence, it became clear their training process made a difference by correcting some beliefs, especially among some female students who had answered them before training with no effect. For the cleanliness of tables where food is eaten and food safety 
Table 2. Results of measuring training on female students' concerns about the risks affecting food safety

\begin{tabular}{|c|c|c|c|c|c|}
\hline \multirow{2}{*}{ The concerns are measured } & \multicolumn{2}{|c|}{ Before training } & \multicolumn{2}{|c|}{ After training } & \multirow{2}{*}{ P-values } \\
\hline & No. & $\%$ & No. & $\%$ & \\
\hline \multicolumn{6}{|l|}{ Clean eating tables } \\
\hline It has an effect & 239 & 95.6 & 247 & 98.8 & \multirow{2}{*}{0.030} \\
\hline It has no effect & 11 & 4.4 & 3 & 1.2 & \\
\hline \multicolumn{6}{|l|}{ Food taste } \\
\hline It has an effect & 155 & 62.0 & 226 & 90.0 & \multirow{2}{*}{0.000} \\
\hline It has no effect & 95 & 38.0 & 24 & 9.0 & \\
\hline \multicolumn{6}{|l|}{ Food Temperature } \\
\hline It has an effect & 189 & 75.6 & 245 & 98.0 & \multirow{2}{*}{0.000} \\
\hline It has no effect & 61 & 24.4 & 24 & 2.0 & \\
\hline \multicolumn{6}{|l|}{ How to provide food } \\
\hline It has an effect & 127 & 50.8 & 215 & 86.0 & \multirow{2}{*}{0.000} \\
\hline It has no effect & 123 & 49.2 & 35 & 14.0 & \\
\hline \multicolumn{6}{|l|}{ Well cooked } \\
\hline It has an effect & 228 & 91.2 & 244 & 97.6 & \multirow{2}{*}{0.002} \\
\hline It has no effect & 22 & 8.8 & 6 & 2.4 & \\
\hline \multicolumn{6}{|l|}{ Freshness of food } \\
\hline It has an effect & 195 & 87.0 & 233 & 93.2 & \multirow{2}{*}{0.000} \\
\hline It has no effect & 55 & 22.0 & 17 & 6.8 & \\
\hline \multicolumn{6}{|l|}{ Cleanliness of serving area } \\
\hline It has an effect & 232 & 92.8 & 241 & 96.4 & \multirow{2}{*}{0.075} \\
\hline It has no effect & 18 & 7.2 & 9 & 3.6 & \\
\hline \multicolumn{6}{|c|}{ Cleanliness of food preparation, production of food } \\
\hline It has an effect & 243 & 97.2 & 247 & 98.8 & \multirow{2}{*}{0.201} \\
\hline It has no effect & 7 & 2,8 & 3 & 1.2 & \\
\hline \multicolumn{6}{|l|}{ Appearance of food handlers } \\
\hline It has an effect & 155 & 62.0 & 225 & 90.0 & \multirow{2}{*}{0.000} \\
\hline It has no effect & 95 & 38.0 & 25 & 10.0 & \\
\hline
\end{tabular}

from epidemics where the correct answers increased to the rate of $98.8 \%(\mathrm{p}=0.030)$.

Another concern that was measured was the cleanliness of the food place provided and well cooked at high temperature as well (92.8 and 91.2\%) respectively, while it was found that after the training of female students there was a positive effect to correct some of the concerns, especially with regard to the correlation between food cooking and safety $(p=0.002)$.

Clean and healthy dining tables are a key component of food safety and several reports have shown that healthy eating conditions are usually measured in the cleanness of a direct eating environment such as a dining table (Kidd, 2000; Grunert, 2005; Sanlier and Kanaklioghi, 2012; Adam et al., 2014) similarly, A clean food environment is also a very important factor as it reveals the general conditions under which food is served. We had a high percentage of respondents who were concerned about the environment and its hygiene.

Students' concern on food temperature as a food safety issue correlated well with the literature on food safety. Mozaffarian and Rimm (2006) and Adam et al. (2014) demonstrated that consumers prefer hot food as the heating process eliminates vegetative forms of foodborne pathogens and thus the risk of foodborne infection. Clean and hygienic eating tables are a key component of food safety and several reports have outlined that hygienic eating conditions are usually measured by the cleanliness of the immediate eating environment such as the dining table (Kidd, 2000; Grunert, 2005; Sanlier and Kanaklioghi, 2012; Adam et al., 2014). Likewise, a clean eating environment is also very important as it projects the overall conditions under which the food is being served. A high percentage of our respondent were concerned about the eating environment and its cleanliness. The results of our investigation highlight the correlation between the appearances of food handlers and food safety. These findings indicate the fact that students also associate the appearance of the food handlers to their food safety practices. A neat, clean and well-dressed food handler is more likely to be following food safety practices than a shabbily dressed one (Rheinländer et al., 2008).

\subsection{Students' cognitive level of correct behaviours to prepare food and its relationship to food poisoning}

The cognitive level (experiences with food preparation and food poisoning) of the students in question was measured using 10 phrases designed to measure knowledge of the correct behaviours of food preparation and their relationship to food poisoning. The 
first phase was an exploratory question about the behaviour of female students in preparing food or participating in preparing it. Each student was given four choices that include: Not participating in preparing it, once a week, daily or sometimes. As for the rest of the phrases were to measure knowledge of the concept of food poisoning and its causes also contained Miscellaneous information on food poisoning and asked each of the students understudy to explain the correctness of the phrase in response to one of the following options: right, wrong, or I don't know. It is also evident from Figure 1 that $46.4 \%$ of respondents sometimes responded with regards to preparing or participating in food themselves. In addition, the equivalent of $29.6 \%$ of the students stated that they prepare or participate in food on a daily basis. As for those who participate in preparing it at a rate of $19.60 \%$, it was for those who participate in preparing it more than once a week, and for the lowest rate, $4.40 \%$ was for those who never participate in preparing food.

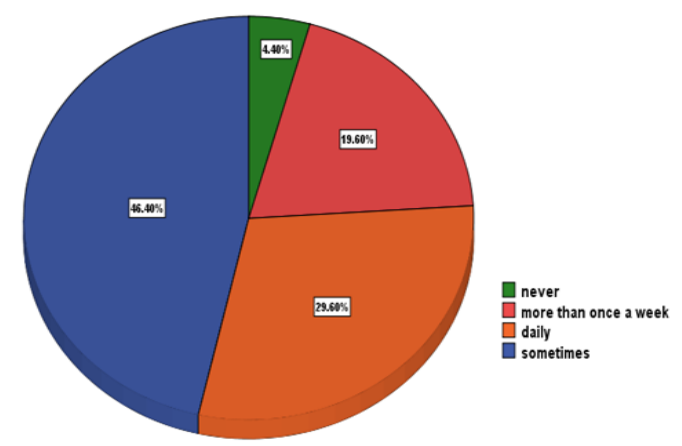

Figure 1. Knowledge of correct behaviours to prepare food and its relationship to food poisoning of the study sample

It is clear from Table 3, that the equivalent of $30.8 \%$ of the participants had previously been exposed to a state of food poisoning during the previous period of their lives. The results also showed that all the students participating in the research before training responded to all the phrases to varying degrees and it was found that the most phrases that were answered correctly, the concept of food poisoning was $92.8 \%$, while the rates were equal to the two phrases, one of which questioned the seriousness of food poisoning on human health, while the other questioned whether there was a relationship between the validity and safety of the water used in preparing food and its safety from diseases, where the proportion was $92.4 \%$.

The answers also varied from the statements that asked about the presence of (more common foods that cause the spread of food poisoning diseases, more prevalent places of food poisoning in them, desire to know about the healthy way to prepare food and the way it is circulated) where the students mentioned correct answers in the following proportions $63.6 \%, 71.2 \%$,
$85.2 \%$, respectively. As for the phrase that was wondering about the degree of food poisoning, whether for food cooked at home or in restaurants, it was the least known statement before training, where the average of correct answers was $8.8 \%$ of the total answers.

The answers also varied from the statements that asked about the presence of (more common foods that cause the spread of food poisoning diseases, more prevalent places of food poisoning in them, desire to know about the healthy way to prepare food and the way it is circulated) where the students mentioned correct answers in the following proportions $63.6 \%, 71.2 \%$, $85.2 \%$, respectively. As for the phrase that was wondering about the degree of food poisoning, whether for food cooked at home or in restaurants, it was the least known statement before training, where the average of correct answers was $8.8 \%$ of the total answers.

\subsection{The students' knowledge of proper food handling}

Table 4 shows the results before and after, in which the students' knowledge level was measured on how to deal with food. The same phrases were used before and after the training process. Each student participating in the research was asked to clarify the validity of the phrase by answering either yes or no. Also, the students were trained using a graphic presentation that contained various information on how to deal with food. In these section 15 questions were used, the answers to which were varied by the students. It also appears through the results in Table 4 that the students had a high level of awareness about some of the phrases that were wondering about how to deal with food. The highest rates for phrases whose correct answer was "yes" before training was for phrases that wonder as follows: "All utensils must be cleaned before eating, surfaces must be cleaned, and dirt and food and microbial residues should be washed, hands should be washed to reduce the risk of contamination, wash the cutting board with detergent and water. Warm-up before using it to cut vegetables if it was previously used to cut raw meat, defects in food containers may cause food damage.". The following percentages are respectively $(99.2 \%, 98.8 \%, 97.6 \%$, $93.2 \%, 90.4 \%)$. As for the phrases that have been answered correctly ended, "none" before the training process for the following phrases (that cooked and uncooked food is placed in the same container in the refrigerator, use one piece of cloth while preparing food to dry hands and wipe dishes and seats) was high (96.0\%, 92.4\%), respectively. However, after training provided to the students, an improvement was observed in the level of correct answers to the two phrases (food with a bad smell or bad appearance is not suitable for eating, defects in food containers may cause food 
Table 3. Results of measuring the impact of training at the cognitive level, female students, with the correct behaviours to prepare food and its relationship to food poisoning

\begin{tabular}{|c|c|c|c|c|c|}
\hline \multirow{2}{*}{ Question } & \multicolumn{2}{|c|}{ Before Training } & \multicolumn{2}{|c|}{ After training } & \multirow{2}{*}{ P-values } \\
\hline & No. & $\%$ & No. & $\%$ & \\
\hline \multicolumn{6}{|c|}{ Have you experienced food poisoning before? } \\
\hline Yes & 77 & 30.8 & 69 & 27.6 & \multirow{3}{*}{0.000} \\
\hline No & 147 & 58.8 & 150 & 60.0 & \\
\hline Don't Know & 26 & 10.4 & 31 & 12.4 & \\
\hline \multicolumn{6}{|c|}{ Do you know what is food poisoning? } \\
\hline Yes & 232 & 92.8 & 240 & 96.0 & \multirow{3}{*}{0.271} \\
\hline No & 13 & 5.2 & 8 & 3.2 & \\
\hline Don't Know & 5 & 2.0 & 2 & 0.8 & \\
\hline \multicolumn{6}{|c|}{ Is food poisoning a risk to human health? } \\
\hline Yes & 231 & 92.4 & 245 & 98.0 & \multirow{3}{*}{0.011} \\
\hline No & 4 & 1.4 & 2 & 0.8 & \\
\hline Don't Know & 15 & 6.0 & 3 & 1.2 & \\
\hline \multicolumn{6}{|c|}{ Is a person affected by food poisoning linked to his personal behaviour? } \\
\hline Yes & 74 & 29.0 & 184 & 73.6 & \multirow{3}{*}{0.000} \\
\hline No & 126 & 50.4 & 52 & 20.8 & \\
\hline Don't Know & 50 & 20.0 & 14 & 5.6 & \\
\hline \multicolumn{6}{|c|}{ Does food cooked at home or in restaurants cause food poisoning to the same degree? } \\
\hline Yes & 22 & 8.8 & 13 & 5.2 & \multirow{3}{*}{0.143} \\
\hline No & 199 & 79.6 & 215 & 86.0 & \\
\hline Don't Know & 29 & 11,6 & 22 & 8.8 & \\
\hline \multicolumn{6}{|c|}{ Is there a relationship between the viability and safety of water used in food preparation and safety? } \\
\hline Yes & 231 & 92.4 & 245 & 98.0 & \multirow{3}{*}{0.011} \\
\hline No & 4 & 1.6 & 2 & 0.8 & \\
\hline Don't Know & 5 & 6.0 & 3 & 1.2 & \\
\hline \multicolumn{6}{|c|}{ Are there more common foods that cause food poisoning? } \\
\hline Yes & 159 & 63.6 & 225 & 90.0 & \multirow{3}{*}{0.000} \\
\hline No & 18 & 7.2 & 4 & 1.6 & \\
\hline Don't Know & 73 & 29.2 & 21 & 8.4 & \\
\hline \multicolumn{6}{|c|}{ Are there more prevalent places for food poisoning? } \\
\hline Yes & 178 & 71.2 & 235 & 94.0 & \multirow{3}{*}{0.000} \\
\hline No & 15 & 6.0 & 1 & 0.4 & \\
\hline Don't Know & 57 & 22.8 & 14 & 5.6 & \\
\hline \multicolumn{6}{|c|}{ Do you want to know more about the healthy way to prepare food and how it is handled? } \\
\hline Yes & 213 & 85.2 & 259 & 83.6 & \multirow{3}{*}{0.001} \\
\hline No & 23 & 9.2 & 39 & 15.6 & \\
\hline Don't Know & 14 & 5.6 & 2 & 0.8 & \\
\hline
\end{tabular}

damage) (95.2\%, 96.4\%), respectively. In which the students showed increased knowledge about how to deal with food to where training has played a role in bringing about this enhancement in their awareness aspect. The results also show an increase in the level of awareness of the phrase that asked whether the person is responsible for food safety after purchase, where the correct rate was $74.8 \%$, as well as training was related to changing some wrong with a rate of $94.0 \%$ In the same context, the training also had a clear impact by increasing female students' knowledge of the effect of high temperature when heating food, as the rate of correct answers after the training process rose to $65.2 \%$ after it was only $42.8 \%$. The findings of the present survey showed an average level of food safety knowledge among students as reported by various workers (Garayoa et al., 2005; Byrd-Bredbenner et al., 2007; Sanlier, 2009; Sharif and Al-Malki, 2010).

\subsection{Evaluation of food handling practices}

There were 15 questions designed to assess the level of female students' behaviour in dealing with food. Each female student participating in the research was asked to clarify the behaviour followed during her handling of any foodstuffs by responding to one of the following options: Always, never, sometimes, which bear the values of $1,2,3$. The results in Table 5 indicate the extent to which students use any type or form of packages to preserve food, so the response rate "sometimes" was the highest $62.8 \%$, followed by the answer "always" where it was $28.8 \%$, While a small number of respondents answered "Never" 8.4\%, and since the training had a correlation with raising the level of correct practices among them, the rate of correct answers for them after training increased $(p=0.000)$. As for practices that state that "no" using an unwashed knife or cutting board where the average of correct answers before training was 94.4\% high and training did not have a correlation where the high level of correct answers after training was very simple $98.0 \%(\mathrm{p}=0.094)$. With regard to the 
Table 4. Results of measuring the impact of training at the female students' knowledge level using food handling methods

\begin{tabular}{|c|c|c|c|c|c|}
\hline \multirow{2}{*}{ Question } & \multicolumn{2}{|c|}{ Before training } & \multicolumn{2}{|c|}{ After training } & \multirow{2}{*}{ P-values } \\
\hline & No. & $\%$ & No. & $\%$ & \\
\hline \multicolumn{6}{|c|}{ The person is responsible for food safety after purchase? } \\
\hline Yes & 187 & 74.8 & 235 & 94.0 & \multirow{2}{*}{0.000} \\
\hline No & 63 & 25.2 & 15 & 6.0 & \\
\hline \multicolumn{6}{|c|}{ All pots must be clean before preparing food? } \\
\hline Yes & 248 & 99.2 & 249 & 99.6 & \multirow{2}{*}{0.563} \\
\hline No & 2 & 0.8 & 1 & 0.4 & \\
\hline \multicolumn{6}{|c|}{ Should you clean utensils and surfaces, remove dirt, food residues and microbes? } \\
\hline Yes & 247 & 98.8 & 250 & 100.0 & \multirow{2}{*}{0.082} \\
\hline No & 3 & 1.2 & 0 & 0 & \\
\hline \multicolumn{6}{|c|}{ Cooked and uncooked food is placed in the same container in the refrigerator? } \\
\hline Yes & 10 & 4.0 & 6 & 2.4 & \multirow{2}{*}{0.309} \\
\hline No & 240 & 96.0 & 244 & 97.6 & \\
\hline
\end{tabular}

If you prepared vegetables on the cutting board and had previously cut raw meat with the same knife, then you must first wash them with detergent and warm water?

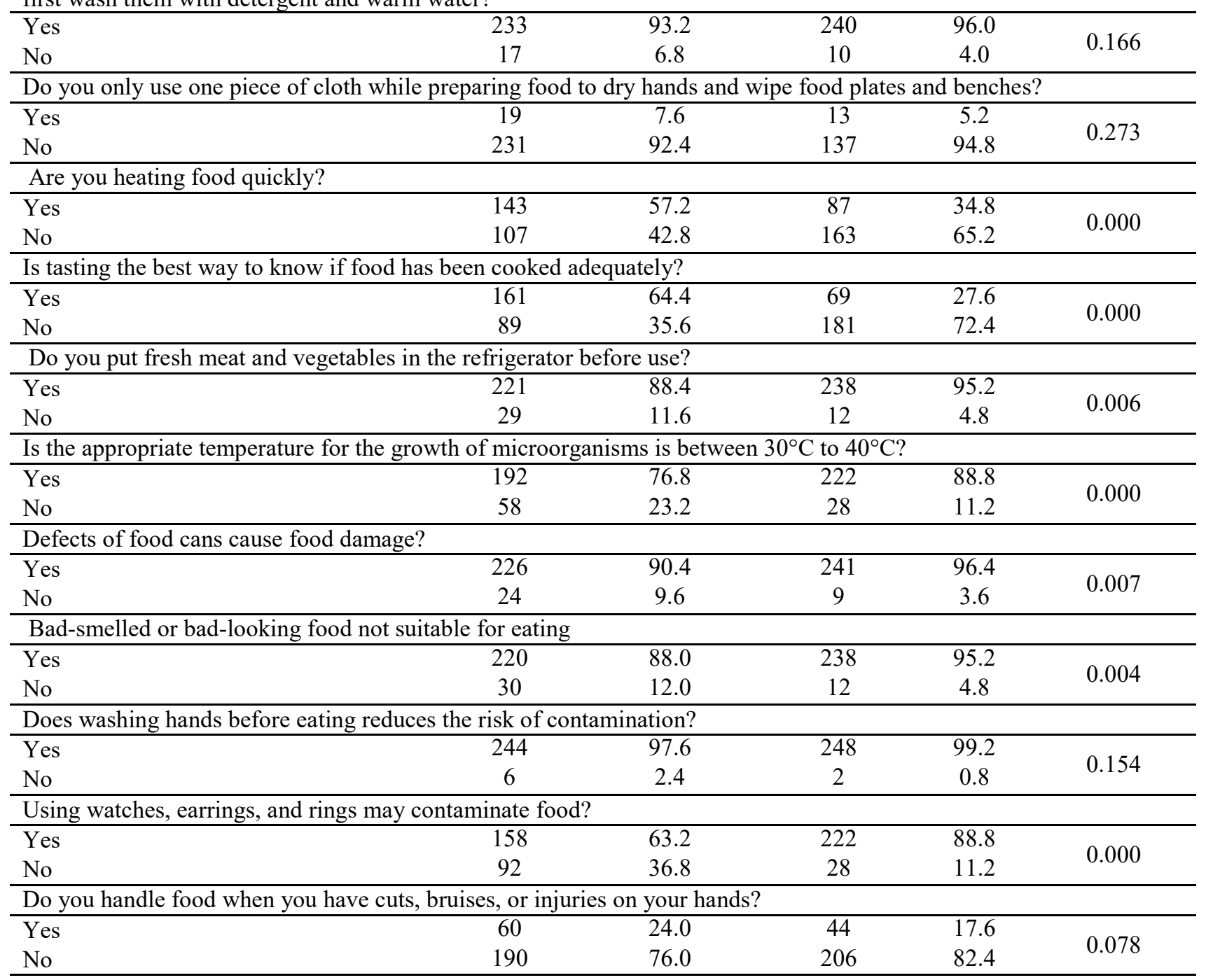

temperature of the refrigerator, $46 \%$ of female students mentioned before training that they "sometimes" check the temperature of the refrigerator before opening it, while the wrong response rate increased to "never" $46.6 \%$, that is, they do not do, while the answer to "sometimes" remained the highest $64 \%$ among female students 'correct response rates after training is due to the influence and correlation of female students training process $(p=0.000)$. Also found in the data of Table 5 were that more than half of the students $52 \%$ answered correctly the phrase that asks that they prepared food if their hands were injured or had bruises with "never" while the data also shows the presence of an effect and a correlation between training and a high rate correct answers $91.2 \%(\mathrm{p}=0.000)$.

The results also indicate that female students practised keeping food residues in the refrigerator before training respondents were "sometimes" $41.6 \%$ while the rest 55.2\% responded with "always" and the lowest rate was "never" 3.2\%. After training, the response rate 
Table 5. Results of measuring the impact of training on female students' practices during food preparation and eating

\begin{tabular}{|c|c|c|c|c|c|}
\hline \multirow{2}{*}{ Question } & \multicolumn{2}{|c|}{ Before training } & \multicolumn{2}{|c|}{ After training } & \multirow{2}{*}{ P-values } \\
\hline & No. & $\%$ & No. & $\%$ & \\
\hline \multicolumn{6}{|c|}{ Do you use any type or form of container to store food? } \\
\hline always & 72 & 28.8 & 40 & 16.0 & \multirow{3}{*}{0.000} \\
\hline never & 21 & 8.4 & 129 & 51.6 & \\
\hline sometimes & 157 & 62.8 & 81 & 32.4 & \\
\hline \multicolumn{6}{|c|}{ Do you use a washed knife or chopping board? } \\
\hline always & 1 & 0.4 & 0 & 0 & \multirow{3}{*}{0.094} \\
\hline never & 236 & 94.4 & 245 & 98.0 & \\
\hline sometimes & 13 & 5.2 & 5 & 2.0 & \\
\hline \multicolumn{6}{|c|}{ Do you check the refrigerator temperature before opening it? } \\
\hline always & 19 & 7.6 & 25 & 10.0 & \multirow{3}{*}{0.000} \\
\hline never & 116 & 46.4 & 64 & 25.6 & \\
\hline sometimes & 115 & 46.0 & 161 & 64.4 & \\
\hline \multicolumn{6}{|c|}{ Do you prepare food if your hands are injured or have bruises? } \\
\hline always & 14 & 5.6 & 0 & 0 & \multirow{3}{*}{0.000} \\
\hline never & 130 & 52.0 & 228 & 91.2 & \\
\hline sometimes & 106 & 42.4 & 22 & 8.8 & \\
\hline \multicolumn{6}{|c|}{ Do you keep food leftovers in the refrigerator? } \\
\hline always & 138 & 55.21 & 61 & 24.4 & \multirow{3}{*}{0.000} \\
\hline never & 8 & 3.2 & 36 & 14.4 & \\
\hline sometimes & 104 & 41.6 & 153 & 61.2 & \\
\hline \multicolumn{6}{|c|}{ Do you clean food serving utensils and utensils with warm water? } \\
\hline always & 137 & 54.8 & 201 & 80.4 & \\
\hline never & 12 & 4.8 & 12 & 4.8 & 0.000 \\
\hline sometimes & 151 & 40.4 & 37 & 14.8 & \\
\hline Do you clean kitchen surface & paring & & & & \\
\hline always & 224 & 89.6 & 238 & 95.2 & \\
\hline never & 2 & 0.8 & 1 & .4 & 0.061 \\
\hline sometimes & 24 & 9.5 & 11 & 4.4 & \\
\hline Do you check the cleanlines & cookin & & & & \\
\hline always & 235 & 94.0 & 244 & 97.6 & \\
\hline never & 1 & 0.4 & 3 & 1.2 & 0.016 \\
\hline sometimes & 14 & 5.6 & 3 & 1.2 & 0.010 \\
\hline Do you remove watches, jew & ooking & & & & \\
\hline always & 135 & 54.0 & 145 & 58.0 & \\
\hline never & 17 & 6.8 & 15 & 6.0 & 0.663 \\
\hline sometimes & 98 & 39.2 & 90 & 36.0 & \\
\hline Do you use expired food? & & & & & \\
\hline always & 6 & 2.4 & 0 & 0 & \\
\hline never & 228 & 91.2 & 234 & 93.6 & 0.048 \\
\hline sometimes & 16 & 6.4 & 16 & 6.4 & \\
\hline Do you wash your hands bef & & & & & \\
\hline always & 237 & 94.8 & 244 & 97.6 & \\
\hline never & 2 & 0.8 & 1 & 0.4 & 0.261 \\
\hline sometimes & 11 & 4.4 & 5 & 2.0 & \\
\hline Are you instructing your par & d safe & & & & \\
\hline always & 132 & 52.8 & 133 & 53.21 & \\
\hline never & 8 & 3.2 & 2 & 0.8 & 0.156 \\
\hline sometimes & 110 & 44.0 & 115 & 46.0 & \\
\hline Do you store cooked and rav & & & & & \\
\hline always & 225 & 90.0 & 245 & 98.0 & \\
\hline never & 7 & 2.8 & 2 & 0.8 & 0.001 \\
\hline sometimes & 18 & 7.2 & 3 & 1.2 & \\
\hline Do you use cracked eggs in 1 & & & & & \\
\hline always & 12 & 4.8 & 10 & 4.0 & \\
\hline never & 199 & 79.6 & 223 & 89.2 & 0.006 \\
\hline sometimes & 39 & 15.6 & 17 & 6.8 & \\
\hline Are you using raw unpasteu & od? & & & & \\
\hline always & 8 & 3.2 & 8 & 3.2 & \\
\hline never & 191 & 76.4 & 230 & 92.0 & 0.000 \\
\hline sometimes & 51 & 20.4 & 12 & 4.8 & \\
\hline
\end{tabular}


sometimes increased to $61.2 \%(\mathrm{p}=0.000)$. While it was found that more than half of the students had "always" correct practices before the training, as well as the training process that was presented contributed to changing some wrong practices, especially about terms that question the extent of (cleaning utensils and tools for providing food with warm water, cleaning kitchen surfaces and utensils after preparing food, checking the cleanliness of utensils before cooking, removing watches, jewellery and rings before cooking, washing hands before cooking, instructing your parents or others regarding food safety practices, storing cooked and raw food separately (with the following proportions) (80.4\%, $95.2 \%, \quad 97.6 \%, \quad 58.0 \%, \quad 53.2 \%, \quad 97.6 \%, \quad 98 \%$ ), respectively. As for the statements that asked about not doing some wrong practices and that their correct answer was "never" such as using (expired foodstuffs, cracked eggs in preparing food, raw unpasteurized raw milk in preparing food), a correlation was found between their high response rates to the correct answer in doing the training in the following proportions $(93.6 \%, 89.2 \%$, $92 \%$ ), respectively. The findings of the present survey showed an average level of food safety knowledge among students as reported by various workers (Garayoa et al., 2005; Byrd-Bredbenner et al., 2007; Sanlier, 2009; Sharif and Al-Malki, 2010). Student's demonstrated good knowledge regarding practices related to the cleanliness of kitchen utensils and kitchen surfaces, prevention of cross-contamination, hand hygiene and checking of food before use. Students displayed poor knowledge regarding heat treatment and temperature control. Our findings are in agreement with those of Sharif and Al-Malki (2010) who showed good food poisoning knowledge score of $75 \%$ among students of Taif University but had limited knowledge on some critical topics related to food safety. Osaili et al. (2011) reported that female college students were most knowledgeable about prevention of crosscontamination and disinfection procedures. Studies have shown that $50.87 \%$ reports of foodborne diseases are associated with domestic kitchen (Redmond and Griffith, 2009). Our results showed good knowledge about preparation, cooking, cooling and storing of food indicating lower risk of occurrence of food-related diseases.

\section{Conclusion}

According to the results of this study, it could be concluded that there is a significant effect of the training program on food safety knowledge and practices among students. It is important that the students have good knowledge and practices related to food safety as they should take care of their food consumption's conditions and handling in regards to creating a healthy individual or even community. At the same time, it could be recommended that there is a necessity to design training programs and interactive educational materials for the community, in general, to enhance the food and health culture through the adoption of this initiative by government agencies, scientific and voluntary societies. Preparing various and intensive awareness and extension campaigns to educate university students in general and women, in particular ways to prevent food poisoning and epidemics that spread through food to achieve safe and sound means of food and health dealings.

\section{References}

Abu Dhabi Food Control Authority. (2010). Essential food safety: A Guide for food handler. Retrieved from website: https://www.adfca.ae/Arabic/ PolicyAndLegislations/Documents/EFST-en.pdf

Adam, I., Hiamey, S.E. and Afenyo, E.A. (2014). Students' food safety concerns and choice of eating place in Ghana. Food Control, 43, 135-141. https:// doi.org/10.1016/j.foodcont.2014.03.005

Al-Shabib, N.A., Mosilhey, S.H. and Husain, F.M. (2016). Cross-sectional study on food safety knowledge, attitude and practices of male food handlers employed in restaurants of King Saud University, Saudi Arabia. Food Control, 59, 212217. https://doi.org/10.1016/j.foodcont.2015.05.002

Byrd-Bredbenner C., Berning, J., Martin-Biggers, J. and Quick, V. (2013). Food Safety in Home Kitchens: A Synthesis of the Literature. International Journal of Environmental Research and Public Health, 10(9), 4060-4085. https://doi.org/10.3390/ijerph10094060

Byrd-Bredbenner, C., Maurer, J., Wheatley, V., Schaffner, D., Bruhn, C. and Blalock, L. (2007). Food safety self-reported behaviours and cognitions of young adults: Results of a national study. Journal of Food Protection, 70, 1917-1926. https:// doi.org/10.4315/0362-028X-70.8.1917

Cruz, C. (2019). Regulatory Disclosure Policies and Potential Induced Changes in Behaviour: An Outcome Evaluation of Sant Clara County's Enhanced Food Safety Program Elements. San Jose State University, USA: MSc. Dissertation.

Ellinda-Patra, M.W., Dewanti-Hariyadi, R. and Nurtama, B. (2020). Modeling of food safety knowledge, attitude, and behaviour characteristics. Food Research, 4(4), 1045 - 1052. https:// doi.org/10.26656/fr.2017.4(4).375

Food Standards Australia New Zealand. (2002). Standard 3.2.2 Food Safety Practices and General Requirements. Retrieved from website: https:// www.foodstandards.gov.au/industry/safetystandards/ safetypractices/Pages/default.aspx

Garayoa, R., Cordoba, M., García-Jalon, I., SanchezVillegas, A. and Vitas, A.I. (2005). Relationship 
between consumer food safety knowledge and reported behaviour among students from health sciences in one region of Spain. Journal of Food Protection, 68(12), 2631-2636. https:// doi.org/10.4315/0362-028X-68.12.2631

Gizaw, Z., Gebrehiwot, M. and Teka, Z. (2014). Food Safety Practice and Associated Factors of Food Handlers Working in Substandard Food Establishments in Gondar Town, Northwest Ethiopia, 2013/14. International Journal of Food Sciences and Nutrition, 3(7), 138-146. https:// doi.org/10.19070/2326-3350-1400027

Grunert, K.G. (2005). Food quality and safety: Consumer perception and demand. European Review of Agricultural Economics, 32(3), 369-391. https:// doi.org/10.1093/eurrag/jbi011

Hassan, F.H. and Dimassi H. (2016). Food safety and handling knowledge and practices of Lebanese university students. Food Control, 40, 127-133. https://doi.org/10.1016/j.foodcont.2013.11.040

Kidd, M. (2000). Food safety- consumer concerns. Nutrition and Food Science, 30(2), 53-55. https:// doi.org/10.1108/00346650010314250

Langiano, E., Ferrara, M., Lanni, L., Viscardi, V., Abbatecola, A.M. and De Vito, E. (2012). Food safety at home: knowledge and practices of consumers. Journal of Public Health, 20(1), 47-57. https://doi.org/10.1007/s10389-011-0437-z

Luo, X., Xu, X., Chen, H., Bai, R., Zhang, Y., Hou, X., Zhang, F., Zhang, Y., Sharma, M., Zeng, H. and Zhao, Y. (2019). Food safety related knowledge, attitudes, and practices (KAP) among the students from nursing, education and medical college in Chongqing, China. Food Control, 95, 181-188. https://doi.org/10.1016/j.foodcont.2018.07.042

Mountjoy, M. (2014). Handbook of Sports Medicine and Science, the Female Athlete. USA: John Wiley and Sons. https://doi.org/10.1002/9781118862254

Mozaffarian, D. and Rimm, E.B. (2006). Fish intake, contaminants, and human health: Evaluating the risk and the benefits. Journal of the American Medical Association, 296(15), 1885-1899. https:// doi.org/10.1001/jama.296.15.1885

Nivethitha R., Vishnupriya, V. and Gayathri, R. (2019). Awareness on food safety knowledge among college students - A survey. Drug Invention Today, 11(9), 2306-2308.

Odeyemi, O.A., Sani, N.A., Obadina, A.O., Saba, C.K.S., Bamidele, F.A., Abughoush, M. and Aberoumand, A. (2019). Food safety knowledge, attitudes and practices among consumers in developing countries: an international survey. Food Research International, 116, 1386-1390. https:// doi.org/10.1016/j.foodres.2018.10.030

Osaili, T.M., Obeidat, B.A., Abu Jamous, D.O.A. and
Bawadi, H.A. (2011). Food safety knowledge and practices among college female students in north of Jordan. Food Control, 22(2), 269-276. https:// doi.org/10.1016/j.foodcont.2010.07.009

Ovca, A., Jevšnik, M. and Raspor, P. (2014). Food safety awareness, knowledge and practices among students in Slovenia. Food Control, 42, 144-151. https:// doi.org/10.1016/j.foodcont.2014.01.036

Redmond, E. and Grjfith, C. (2009). Good practice for food handlers and consumers, in Foodborne Pathogens, Hazards, Risk Analysis and Control. 2nd ed., p. 518-543. USA: Woodhead Publishing Series in Food Science, Technology and Nutrition. https:// doi.org/10.1533/9781845696337.1.518

Rheinländer, T., Olsen, M., Abubakar, J., Takyi, H.B., Konradsen, F. and Samuelsen, H. (2008). Keeping up appearances: Perceptions of street food safety in urban Kumasi, Ghana. Journal of Urban Health, 85 (6), 952e964. https://doi.org/10.1007/s11524-0089318-3

Sanlier, N. (2009). The knowledge and practice of food safety by young and adult consumers. Food Control, 20(6), 538-542. $\quad$ https://doi.org/10.1016/ j.foodcont.2008.08.006

Sanlier, N. and Konaklioglu, E. (2012). Food safety knowledge, attitude and food handling practices of students. British Food Journal, 114(4), 469-480. https://doi.org/10.1108/00070701211219504

Sayuti, Y.A., Albattat, A., Ariffin, A.Z., Nazrin, N.S. and Silahudeen, T.N.A.T. (2020). Food safety knowledge, attitude and practices among management and science university students, Shah Alam. Management Science Letters, 10, 929-936. https://doi.org/10.5267/j.msl.2019.10.002

Sharif, L. and Al-Malki, T. (2010). Knowledge, attitude and practice of Taif University students on food poisoning. Food Control, 21(1), 55- 60. https:// doi.org/10.1016/j.foodcont.2009.03.015

Singh, A. and Masuku, M. (2014). Sampling Techniques and Determination of Sample Size in Applied Statistics Research: an Overview. International Journal of Commerce and Management, 2(11), 1-22.

Tirado, M.C. and Schmidt, K. (2001). WHO Surveillance Programme for Control of Foodborne Infections and Intoxications: Preliminary Results and Trends Across Greater Europe. Journal of Infection, 43(1), 80-84. https://doi.org/10.1016/S0163-4453 (01)90861-8

Young, I. and Waddel, L. (2016). Barriers and Facilitators to Safe Food Handling among Consumers: A Systematic Review and Thematic Synthesis of Qualitative Research Studies PLOS ONE, 11(12), e0167695. https://doi.org/10.1371/ journal.pone.0167695 